Article

\title{
Effects of Biodiesel Blend on Marine Fuel Characteristics for Marine Vessels
}

\author{
Cherng-Yuan Lin \\ Department of Marine Engineering, National Taiwan Ocean University, Keelung 202, Taiwan; \\ E-Mail: lin7108@ntou.edu.tw; Tel./Fax:+886-2-24622307
}

Received: 12 July 2013; in revised form: 12 September 2013 / Accepted: 16 September 2013 /

Published: 24 September 2013

\begin{abstract}
Biodiesel produced from vegetable oils, animal fats and algae oil is a renewable, environmentally friendly and clean alternative fuel that reduces pollutants and greenhouse gas emissions in marine applications. This study investigates the influence of biodiesel blend on the characteristics of residual and distillate marine fuels. Adequate correlation equations are applied to calculate the fuel properties of the blended marine fuels with biodiesel. Residual marine fuel RMA has inferior fuel characteristics compared with distillate marine fuel DMA and biodiesel. The flash point of marine fuel RMA could be increased by $20 \%$ if blended with $20 \mathrm{vol} \%$ biodiesel. The sulfur content of residual marine fuel could meet the requirement of the 2008 MARPOL Annex VI Amendment by blending it with 23.0 vol\% biodiesel. In addition, the kinematic viscosity of residual marine fuel could be reduced by $12.9 \%$ and the carbon residue by $23.6 \%$ if $20 \mathrm{vol} \%$ and $25 \mathrm{vol} \%$ biodiesel are used, respectively. Residual marine fuel blended with 20 vol\% biodiesel decreases its lower heating value by $1.9 \%$. Moreover, the fuel properties of residual marine fuel are found to improve more significantly with biodiesel blending than those of distillate marine fuel.
\end{abstract}

Keywords: biodiesel; fuel blending; environmental impact; emission reduction

\section{Introduction}

Marine fuel characteristics are rather inferior to those of diesel fuel in on-road applications, primarily with a view to fuel cost savings in marine transportation [1]. Marine fuel has a relatively higher kinematic viscosity, pour point and density, in addition to a much lower heating energy, fluidity and cetane number [2]. Moreover, high levels of asphalt, fuel residue, sulfur content, metallic 
compounds and unburnable impurities are generally contained in marine bunker oil [3]. The continuous enhancement of the international trade of goods has increased marine fuel consumption. It has been estimated that as much as $10 \%-20 \%$ of global petroleum-derived fuel is consumed in the marine application [4]. In consequence, the amounts of various pollutant emissions from marine vessels are too significant to be ignored, as they are responsible for $4 \%-9 \%, 14 \%-31 \%$ and $3 \%-6 \%$ of global sulfur oxide $\left(\mathrm{SO}_{x}\right)$, nitrogen oxides $\left(\mathrm{NO}_{x}\right)$ and carbon dioxide $\left(\mathrm{CO}_{2}\right)$ emissions, respectively [5]. Although the Marine Environment Protection Committee (MEPC) of the International Maritime Organization (IMO) has made great efforts to reduce air pollution caused by oceangoing vessels, a much more stringent measure is appealing due to the increased global awareness about environmental protection, climate change and human health concerns [6].

The fuel properties of residual fuel can be adjusted by blending it with a clean, renewable and environmentally friendly alternative fuel to alleviate pollutant emissions from marine vessels. Biodiesel is miscible with petroleum-derived fuel and can be mixed with marine fuel in any proportion to burn in marine diesel engines without requiring major engine modifications [7]. Other advantages of biodiesel include higher biodegradability, superior lubricity for engine parts, lower greenhouse gas emissions and more efficient combustion levels [8]. Hence, biodiesel could be an adequate alternative fuel candidate for emissions reduction in marine applications. Vegetable oils such as rapeseed, soybean and palm oil, algae oil, animal fats and agricultural waste, which are primarily composed of triglycerides, are frequently used to produce biodiesel, which is also known as fatty acids methyl esters (FAME).

The application of clean alternative fuels such as biodiesel in marine vessels is still very limited compared with its widespread land-based applications. The relatively higher fuel cost of biodiesel compared with marine fuel is one of the major obstacles to its successful development in marine applications. A lower blending ratio of biodiesel such as below B20 (i.e., 20 vol\% biodiesel with remaining petroleum-derived fuel) in marine fuel oil could reduce fuel costs for ship owners. A few mathematical models have been proposed in the literature to calculate the binary mixture of biodiesel with petroleum-derived fuel. Mejia et al. [9] developed empirical models to evaluate fuel properties of kinematic viscosity, cloud point and flash point of binary mixtures of palm oil biodiesel or castor oil biodiesel and diesel fuel. They found a blended fuel equation of kinematic viscosity proposed by Krisnangkura et al. [10] agreed satisfactorily with their experimental data. Hence, the correlation equation of kinematic viscosity of blended fuel which has logarithmic relation with each component in the blend was used in this study. Regarding to flash point of blended fuel, Benjumea et al. [11] and Mejia [9] confirmed that a correlation equation termed as Kays rule can fit their experimental data more satisfactorily. Therefore, Kays rule is applied in this study to calculate the flash point of blended fuel.

Saxena et al. [12] extensively compared different models for predicting properties of biodiesel and their blends such as cloud point, vapor pressure, and density. They considered it is still difficult to justify the best prediction model primarily because those model-equations were proposed based on different type and composition of biodiesel. Tesfa et al. [13] developed a correlation equation between density and kinematic viscosity for a variety of biodiesels, which is dependent on the type and percentage of biodiesel, environmental temperature and density, etc. They adopted a similar prediction equation to that of Krisnangkura et al. [10] to estimate the kinematic viscosity of biodiesel blend.

Garcia et al. [14] attempted to establish adequate models to predict biodiesel properties for a continuous biodiesel production process using Aspen HYSYS V7.0 software (Aspen Technology Inc., 
Burlington, MA, USA). They considered that a mixing rule [15] is reliable to calculate heating value of blended biodiesel. The lower heating value (LHV), sulfur content, and carbon residue of the blended marine fuel with biodiesel will thus be estimated based on this equation of mixing rule in this study. Tesfa et al. [16] proposed a prediction model for predicting LHV of biodiesel blends. The LHV of biodiesel blends is only varied with biodiesel fraction but independent with the LHV of each mixture component including neat biodiesel and diesel in their prediction equation. Hence, their prediction equation may be only applicable to their specific biodiesel and diesel.

Although the fuel properties of marine fuel might be improved by blending with biodiesel, there is still no study to predict fuel characteristics of the blended marine fuel with biodiesel in the literature. Moreover, reliable calculation models and correlation equations for key fuel characteristics of binary mixture of marine fuel with biodiesel have not been found as yet. Hence, the effect of using a biodiesel blend in marine vessels on fuel characteristics will be investigated in this study. Adequate calculation methods for significant blended fuel properties such as LHV, carbon residue, and flash point will be established. The application potential of marine fuel blended with biodiesel for marine vessels will be further evaluated based on the calculated property results of the blended marine fuel in this study.

\section{Calculation Methods for Determining Blended-Fuel Properties}

Table 1 compares the fuel specifications of the ISO 8217 fuel standards for residual marine fuel (RMA) and marine distillate fuel (DMA) [17] and the biodiesel specifications of EN14214 [18]. It is obvious that the fuel properties of DMA and RMA, and particularly the latter, are far inferior to those of biodiesel.

Table 1. Fuel properties of the specification ISO 8217 RMA for residual marine fuel and DMA for distillate marine fuel and the specification EN 14214 for biodiesel.

\begin{tabular}{ccccc}
\hline Fuel parameter & Unit & ISO8217 RMA & ISO8217 DMA & EN 14214 biodiesel \\
\hline Cetane number, min & - & 20 & 40 & 51 \\
Sulfur, max & $\mathrm{ppmw}$ & 45,000 & 15,000 & 10 \\
Density $\left(\right.$ at $\left.15{ }^{\circ} \mathrm{C}\right)$ & $\mathrm{kg} / \mathrm{m}^{3}$ & $920 \mathrm{max}$ & $890 \mathrm{max}$ & 860 to 900 \\
Flash point, $\min$ & ${ }^{\circ} \mathrm{C}$ & 60.0 & 60.0 & 120.0 \\
Carbon residue, $\max$ & $\mathrm{wt} \%$ & 2.5 & 0.3 & $0.05 *$ \\
Kinematic viscosity $\left(\right.$ at $\left.40{ }^{\circ} \mathrm{C}\right)$ & $\mathrm{mm}^{2} / \mathrm{s}$ & $10.0 \mathrm{max}$ & 2.0 to 6.0 & 3.5 to 5.0 \\
Heating value & $\mathrm{MJ} / \mathrm{kg}$ & 40 & 42 & 38 \\
Water content, max & $\mathrm{ppm}$ & 3,000 & - & 500 \\
Acid number, max & $\mathrm{mg} \mathrm{KOH} / \mathrm{g}$ & 2.5 & 0.5 & 0.5 \\
\hline
\end{tabular}

* based on the ASTM 6751-11a specification.

The fuel characteristics of RMA are the worst among the three fuels listed in Table 1. This study considers the variations in the properties of marine fuel, including its flash point, sulfur content, kinematic viscosity, carbon residue and lower heating value, along with the biodiesel blending ratio. The flash point of blended marine fuel RMA or DMA with biodiesel are calculated based on the correlation equation of Kays rule [9,11] as shown below:

$$
\mathrm{T}_{\mathrm{fb}}=x \times \mathrm{T}_{\mathrm{f} 1}+(1-x) \times \mathrm{T}_{\mathrm{f} 2}
$$


where $\mathrm{T}_{\mathrm{fb}}$ is the flash point of the blended marine fuel, $x$ is the molar or volumetric fraction of the biodiesel in the marine fuel. $\mathrm{T}_{\mathrm{fl}}$ and $\mathrm{T}_{\mathrm{f} 2}$ are the flash points of the biodiesel and marine fuel oils DMA or RMA, respectively, as shown in Table 1.

Lower heating value (LHV) is the amount of heat release from fuel burning without the condensing heat of water vapor to liquid vapor. LHV is generally derived by deducting vaporization heat of water vapor from its corresponding higher heating value ( $\mathrm{HHV}$ ) in a unit of cal $/ \mathrm{g}$ or $\mathrm{MJ} / \mathrm{kg}$. In addition, fuel sulfur content is defined as the amount of sulfur united with fuel and carbon residue is the amount of carbonaceous material left after burning process. The values of LHV, sulfur content and carbon residue are generally expressed on a weight base. Hence, mixing rule previously applied by García et al. and Clements [14,15] are adequate to calculate those three properties of blended marine fuel with biodiesel. The calculation formula can be given in the following form:

$$
\mathrm{S}_{\mathrm{b}}=y \times \mathrm{S}_{1}+(1-y) \times \mathrm{S}_{2}
$$

where $S_{b}$ is the blended fuel property on a weight base, including LHV, carbon residue and sulfur content in this study; $S_{1}$ and $S_{2}$ are the corresponding fuel property such as fuel sulfur contents of the biodiesel and marine fuel. Mass fraction $y$ of the biodiesel is used in Equation (2). Since volume proportion of the biodiesel in marine fuel RMA and DMA is varied in this study, the mass fraction $y$ will be converted from volume fraction $\mathrm{x}$ of the biodiesel based on the following equation before Equation (2) is used to calculate blended fuel properties:

$$
\mathrm{y}=x \times \rho_{1} /\left[x \times \rho_{1}+(1-x) \times \rho_{2}\right]
$$

where $\rho_{1}$ and $\rho_{2}$ are the densities of the biodiesel and marine fuel respectively, as shown in Table 1.

Grun-Nissan viscosity equation applied by Tesfa et al. [13] is taken to compute the kinematic viscosity of the blended fuel, which is given below:

$$
\ln v_{\mathrm{b}}=x \times \ln v_{1}+(1-x) \times \ln v_{2}
$$

where $v_{b}$ is the kinematic viscosity of the blended fuel; $v_{1}$ and $v_{2}$ are the kinematic viscosities of the biodiesel and marine fuel, respectively.

\section{Results and Discussion}

\subsection{Flash Point}

The flash point is a significant safety indicator during the storage, transportation and operation of fuel. Naval marine fuel, which has a flash point of below $60{ }^{\circ} \mathrm{C}$, is not allowed to be stowed below deck according to the IMO Safety of Life at Sea (SOLAS) Convention [19]. As shown in Table 1, the minimum flash point specified in ISO 8217 RMA and DMA is $60^{\circ} \mathrm{C}$. The flash point of biodiesel is generally significantly higher than those of petroleum-derived fuels. Soybean methyl ester (SME), the biodiesel made from soybean oil feedstock, may have a flash point as high as $138{ }^{\circ} \mathrm{C}$ or more [20]. The minimum flash point of biodiesel based on the EN14214 specification is $120^{\circ} \mathrm{C}$.

As shown in Figure 1, the flash points of the residual marine fuel oil RMA and distillate marine fuel DMA blends which are computed based on the correlation equation of Kays rule [9,11] increase significantly with the volume proportions of the biodiesel in the marine fuel. Figure 1 also indicates 
that the blending of $20 \mathrm{vol} \%$ biodiesel in the marine fuel could increase its flash point considerably by $20 \%$. The flash point of marine fuel DMA or RMA blended with at least 5 vol $\%$ biodiesel could reach $63{ }^{\circ} \mathrm{C}$ or above, which can not only conform to the IMO SOLAS Convention [19] but also reduce the extent of problems such as fire hazards, which can be caused by the lower flash point of fuel.

Figure 1. Variation of flash point with volume fraction of biodiesel blends in distillate marine fuel DMA and residual marine fuel RMA.

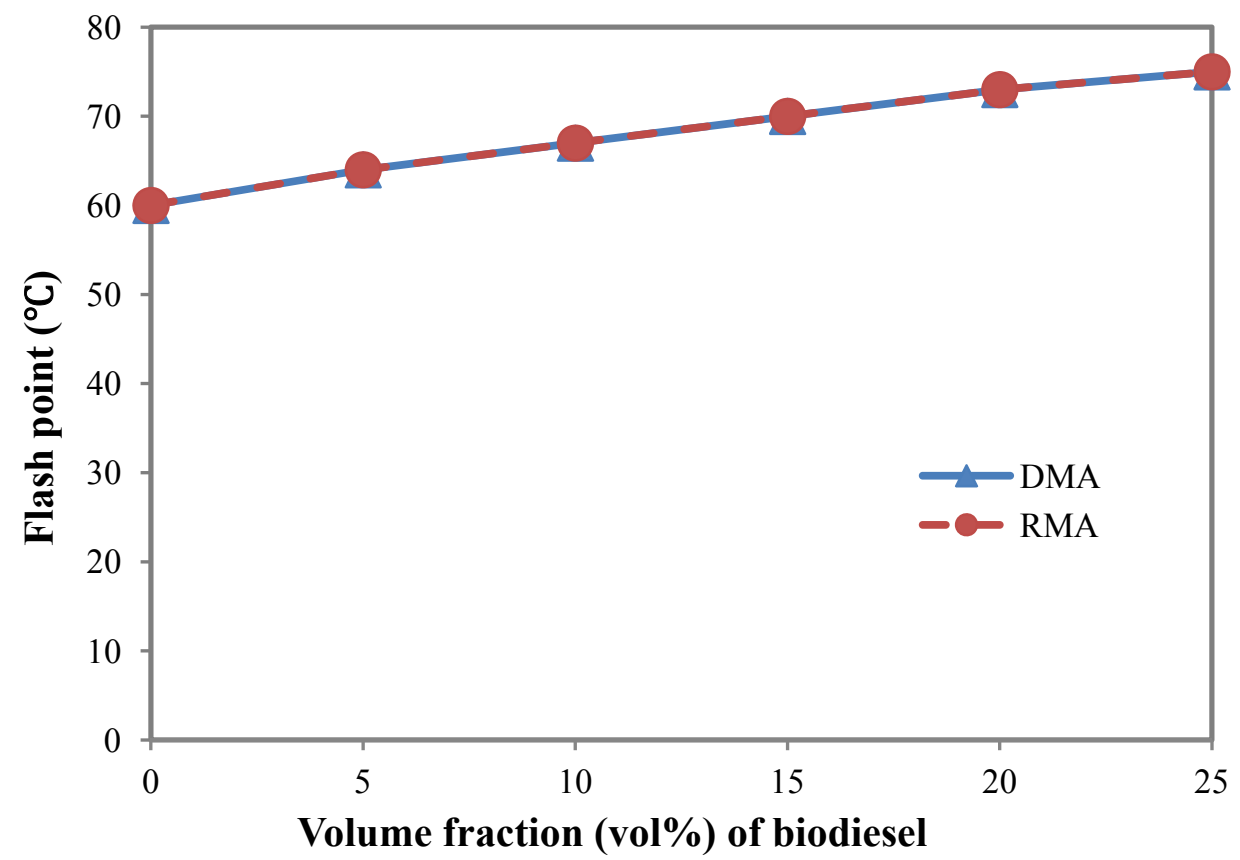

\subsection{Sulfur Content}

Because biodiesel has almost no sulfur content, the blending of marine fuel oil with biodiesel can significantly reduce the former's sulfur content and thus reduce the emission of sulfur oxides $\left(\mathrm{SO}_{x}\right)$ after fuel burning. The sulfur content of the blended marine fuel was calculated by mixing rule based on the weight proportions of the mixture components [14,15]. For example, if $23.0 \mathrm{vol} \%$ biodiesel is added to the residual marine fuel oil RMA as shown in Figure 2, the sulfur content of $4.5 \mathrm{wt} \%$ in marine residual fuel can be reduced to $3.5 \mathrm{wt} \%$, which would meet the 2012 sulfur content requirement of the 2008 MARPOL Annex VI Amendment [21]. The ship's owner can therefore save much capital expenditure on installing an exhaust gas after-treatment system such as a flue gas desulfurization (FGD) system for reducing sulfur oxides $\left(\mathrm{SO}_{x}\right)$ emissions from marine main diesel engines. Hence, $23.0 \mathrm{vol} \%$ biodiesel in marine fuel is considered an economic blending fraction. Moreover, as shown in Figure 2, the fuel sulfur content of distillate marine fuel DMA is reduced from $1.5 \mathrm{wt} \%$ by $24.78 \%$ if $25 \mathrm{vol} \%$ biodiesel is blended with the marine fuel. In addition, blending biodiesel into petroleum-derived diesel can also improve the latter's lubricity characteristics.

Fuel sulfur not only increases $\mathrm{SO}_{x}$ emissions, but also lubricates the moving parts of engines. Hence, the reduction of the fuel sulfur content in petroleum-derived diesel decreases $\mathrm{SO}_{x}$ emissions in the fuel combustion process and also considerably decreases its lubricity [22]. The addition of as little 
as $2 \%$ biodiesel into marine diesel fuel would significantly improve the lubricity of the moving parts of a marine engine [23].

Figure 2. Variation of sulfur content with volume fraction of biodiesel blends in distillate marine fuel DMA and residual marine fuel RMA.

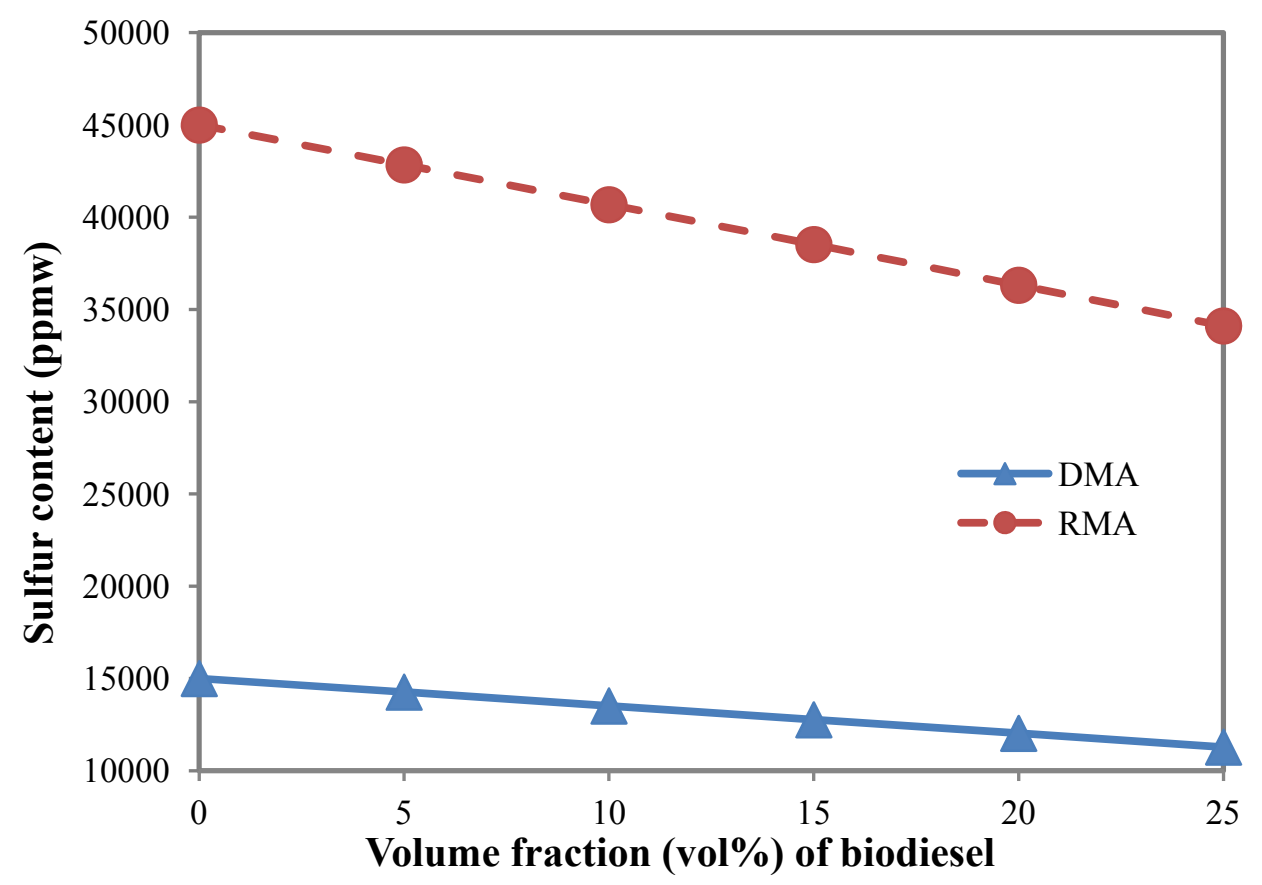

\subsection{Kinematic Viscosity}

The ISO 8217 RMA residual fuel is revealed to have the largest value of kinematic viscosity among the three fuels in Table 1, reaching $10 \mathrm{~mm}^{2} / \mathrm{s}$ (i.e., cSt), about 2-3 times that of biodiesel. A large amount of heating or pumping energy is required to heat the residual fuel and thereby reduce its viscosity and increase fluidity so it can flow through fuel feeding systems and be injected into a marine diesel engine for atomization and burning.

The kinematic viscosity of the blended marine fuel with biodiesel is calculated by a Grun-Nissan viscosity equation [13]. As shown in Figure 3, the blending of residual marine fuel with biodiesel can significantly reduce its kinematic viscosity so that much less heating or pumping energy is required. Figure 3 also indicates that the kinematic viscosity could be reduced by $12.9 \%$ if 20 vol\% biodiesel were blended into residual marine fuel RMA. In addition, as Figure 3 shows, the kinematic viscosity of blended residual marine fuel oil RMA decreases much more significantly with the increase of the biodiesel blending ratio in comparison with that of blended distillate marine fuel DMA. 
Figure 3. Variation of kinematic viscosity with volume fraction of biodiesel blends in distillate marine fuel DMA and residual marine fuel RMA.

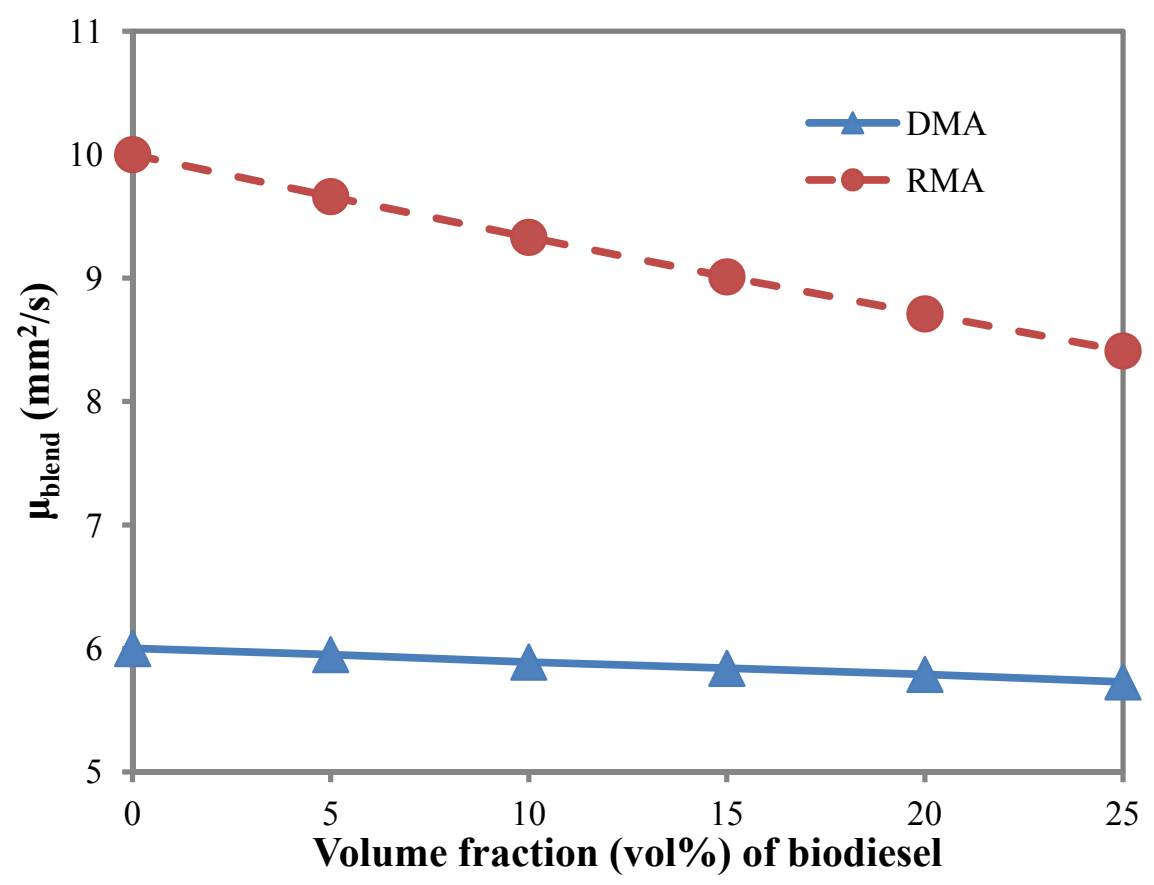

\subsection{Carbon Residue}

The amount of carbon residue left after the fuel burning process is a major indicator of the extent of the complete combustion of liquid fuel. The carbon residue calculation is based on the following formula: carbon residue $(\mathrm{wt} \%)=$ the weight of the collected carbon residue after fuel burning/the initial weight of the liquid fuel before burning. A lower carbon residue implies a higher level of complete combustion, and thus is preferable for liquid fuel [24]. The blending of residual marine fuel RMA with biodiesel causes a significant reduction in the carbon residue and enhances the combustion characteristics of degraded marine fuel. The carbon residue may be produced from the incomplete burning out of impurities, catalysts, additives and ash in liquid fuel. Aromatic compounds in petroleum-derived fuel also contribute to the formation of carbon residue and black smoke [25] after the fuel burning. Carbon residue may be deposited and accumulate inside the combustion chamber or piston ring, leading to more black smoke production in the exhaust manifold, a wearing down of the engine cylinder liner and a more rapid breakdown of the engine.

As Table 1 shows, residual marine fuel RMA may release as much as $2.5 \mathrm{wt} \%$ carbon residue, much higher than the $0.05 \mathrm{wt} \%$ carbon residue left after burning biodiesel. This means that the formation of carbon residue from marine fuel RMA could be as high as 50 times that of biodiesel. The much lower carbon residue from biodiesel is attributed to the FAME in its composition, which contains much less ash, fewer impurities and almost no aromatic compounds [26]. The higher level of oxygen in biodiesel compared with marine fuel also leads to more complete burning and much less carbon residue formation after the burning process. As Figure 4 shows, the carbon residue of residual marine fuel RMA could be reduced from $2.5 \mathrm{wt} \%$ to $1.91 \mathrm{wt} \%$, equivalent to a $23.6 \%$ reduction, after 25 vol\% biodiesel is blended into the RMA. 
Figure 4. Variation of carbon residue with volume fraction of biodiesel blends in distillate marine fuel DMA and residual marine fuel RMA.

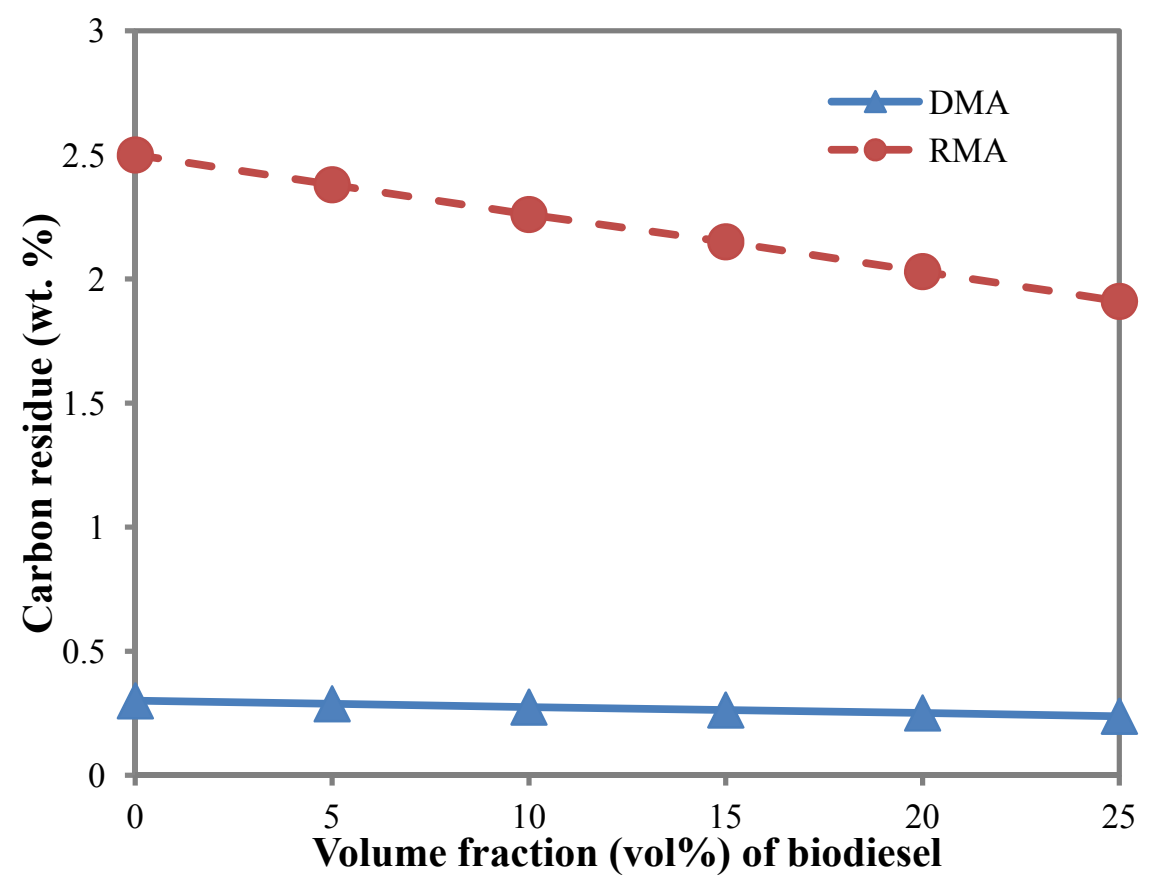

\subsection{Lower Heating Value (LHV)}

Heating value is the amount of heat release from a complete exothermic reaction during fuel burning. Although higher heating value (HHV) is widely applied in combustion practices, lower heating value (LHV) is usually used in estimation models of automotive fuel and engine performance due to negligible amount of water vapor produced from such fuel [27,28]. Hence, LHV of blended marine fuel with biodiesel is computed and discussed in this study. Biodiesel is shown to have lower LHV than DMA and RMA in Table 1. This is attributed to that biodiesel generally has less elemental carbon content in comparison with that of petroleum-derived fuel by about $10 \mathrm{wt} \%$. The less elemental carbon content of biodiesel is compensated by around $10 \mathrm{wt} \%$ more elemental oxygen content. Hence, biodiesel generally is burned much more efficiently and releases much less carbon oxides and greenhouse gas emissions.

Lower inherent energy content of fuel implies lower output of engine horsepower or inferior fuel economy. It was reported previously [13] that about 1.9\%-2.7\% LHV loss for diesel vehicles fuelled with B20 diesel (i.e., 20 vol $\%$ biodiesel with diesel). The lower heating values are decreased by $1.9 \%$ and $0.1 \%$, respectively after 20 vol\% biodiesel is blended into DMA and RMA as shown in Figure 5. Hence, the results of decreased LHV of the blended marine fuel in this study agree well with those of diesel blended with biodiesel. 
Figure 5. Variation of lower heating value (LHV) with volume fraction of biodiesel blends in distillate marine fuel DMA and residual marine fuel RMA.

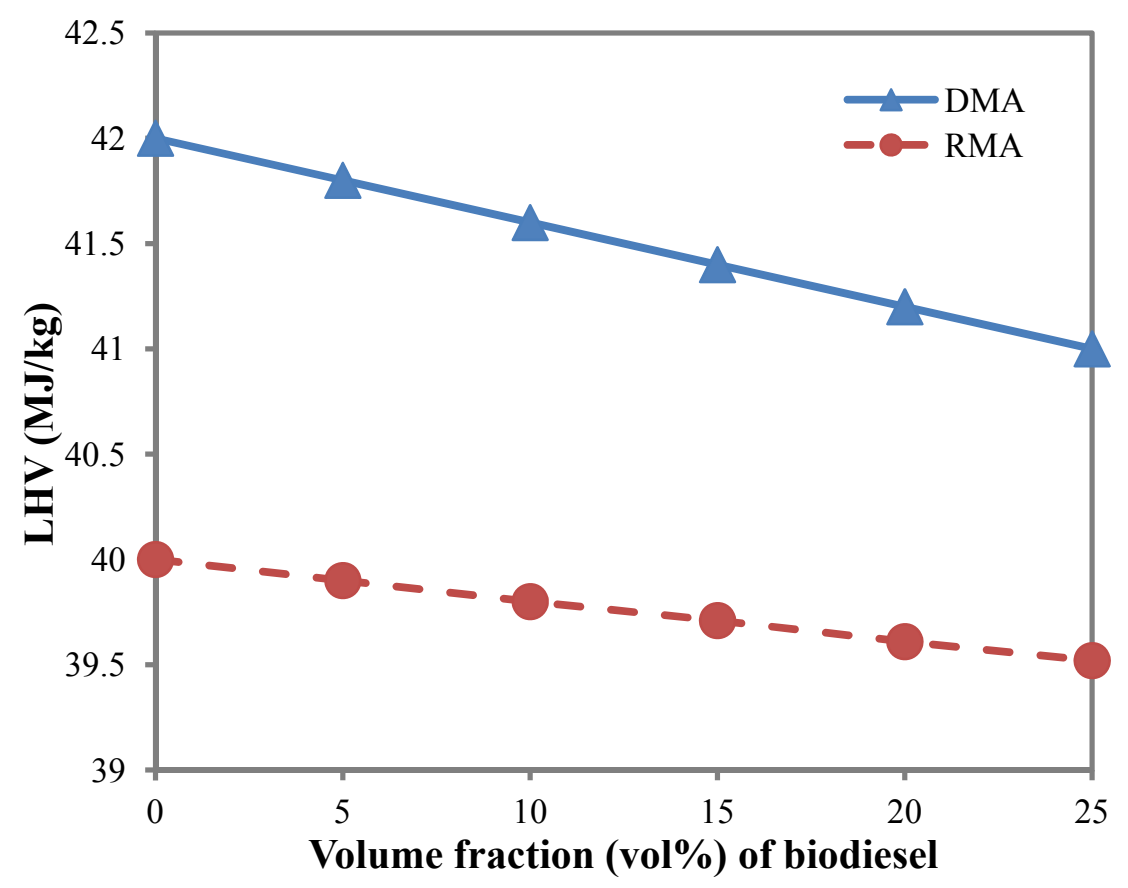

\section{Conclusions}

This study investigates the influences of biodiesel blending in distillate marine fuel DMA and residual marine fuel RMA on fuel properties. The main conclusions are summarized as follows.

(1) Residual marine fuel RMA has the worst fuel characteristics compared with distillate marine fuel DMA and biodiesel. Biodiesel blending could improve the fuel properties of residual marine fuel RMA more significantly compared with distillate marine fuel DMA.

(2) Biodiesel has a significantly higher flash point than marine fuels DMA and RMA. A 20 vol\% biodiesel blending in marine fuel RMA could increase its flash point by $20 \%$, thus increasing fuel safety during operation and storage periods.

(3) The fuel sulfur limit of marine fuel oil reaches as high as $4.5 \mathrm{wt} \%$ based on the ISO 8217 specification of residual marine fuel. Biodiesel contains almost no sulfur. Only a $23.0 \mathrm{vol} \%$ biodiesel blending in marine fuel RMA would reduce the sulfur content to below $3.5 \mathrm{wt} \%$, which would meet the requirement of the 2008 MARPOL Annex VI Amendment [21].

(4) Biodiesel blending decreases the kinematic viscosity of marine fuel. A $20 \mathrm{vol} \%$ biodiesel blending in marine fuel RMA could reduce its kinematic viscosity by $12.9 \%$.

(5) Much less carbon residue is released after the burning of biodiesel compared with marine fuel RMA. The carbon residue could be decreased by $23.6 \%$ if $25 \mathrm{vol} \%$ biodiesel were blended into residual marine fuel RMA. The combustion characteristics of the blended marine fuel would also be greatly improved.

(6) The lower heating value of the blended marine fuel DMA and RMA with $20 \mathrm{vol} \%$ biodiesel is found to decrease by $1.9 \%$ and $0.1 \%$, respectively. 


\section{Acknowledgments}

The author acknowledges the financial support from the National Science Council of Taiwan, under project Nos. NSC100-2622-E-019-004-CC3, NSC97-2628-E-019-016-MY2, and NSC1002622-E-019-029-MY3.

\section{Conflicts of Interest}

The author declare no conflict of interest.

\section{References}

1. Lin, C.Y.; Huang, T.H. Cost-benefit evaluation of using biodiesel as an alternative fuel for fishing boats in Taiwan. Mar. Policy 2012, 36, 103-107.

2. Nayyar, P. The Use of Biodiesel Fuels in the U.S. Marine; Report for the U.S. Maritime Administration (MARAD); Prime Inc.: Washington, DC, USA, 2010; pp. 65-79.

3. Lin, C.Y.; Chen, W.C. Effects of potassium sulfide content in marine diesel fuel oil on emission characteristics of marine furnaces under varying humidity of inlet air. Ocean Eng. 2006, 33, 1260-1270.

4. Deniz, C.; Kilic, A.; Civkaroglu, G. Estimation of shipping emissions in Candarli Gulf, Turkey. Environ. Monit. Assess. 2010, 171, 219-228.

5. Eyring, V.; Köhler, H.W.; van Aardenne, J.; Lauer, A. Emissions from international shipping: The last 50 years. J. Geophys. Res. 2005, 110, D17305.

6. Prpic, J.; Faltinsen, O.D. Estimation of ship speed loss and associated $\mathrm{CO}_{2}$ emission in a seaway. Ocean Eng. 2012, 44, 1-10.

7. Jaichandarl, S.; Annamalai, K. The status of biodiesel as an alternative fuel for diesel engine-An overview. J. Sust. Energy Environ. 2011, 2, 71-75.

8. Usta, N.; Aydogan, B.; Con, A.H.; Uguzdogam, E.; Ozkal, S.G. Properties and quality verification of biodiesel produced from tobacco seed oil. Energy Convers. Manag. 2011, 52, 2031-2039.

9. Mejia, J.D.; Salgado, N.; Orrego, C.E. Effect of blends of diesel and palm-castor biodiesels on viscosity, cloud point and flash point. Ind. Crop. Prod. 2012, 43, 791-797.

10. Krisnangkura, K.; Yimsuwan, T.; Pairintra, R. An empirical approach in predicting biodiesel viscosity at various temperatures. Fuel 2006, 85, 107-113.

11. Benjumea, P.; Agudelo, J.; Agudelo, A. Basic properties of palm oil biodiesel-diesel blends. Fuel 2008, 87, 2069-2075.

12. Saxena, P.; Jawale, S.; Joshipura, M.H. A review on prediction of properties of biodiesel and blends of biodiesel. Proc. Eng. 2013, 51, 395-402.

13. Tesfa, B.; Mishra, R.; Gu, F.; Powles, N. Prediction models for density and viscosity of biodiesel and their effects on fuel supply system in CI engines. Renew. Energy 2010, 35, 2752-2760.

14. García, M.; Gonzalo, A.; Sánchez, J.L.; Arauzo, J.; Peña, J.A. Prediction of normalized biodiesel properties by simulation of multiple feedstock blends. Bioresour. Technol. 2010, 101, 4431-4439. 
15. Clements, L.D. Blending Rules for Formulating Biodiesel Fuel. In Liquid Fuel and Industrial Products from Renewable Resources, Proceedings of the 3rd Liquid Fuels Conference, Nashville, TN, USA, 15-16 September 1996; American Society of Agricultural and Engineers: St. Joseph, MI, USA, 1996; p. 44.

16. Tesfa, B.; Gu, F.; Mishra, R.; Ball, A.D. LHV predication models and LHV effect on the performance of CI engine running with biodiesel blends. Energy Convers. Manag. 2013, 71, 217-226.

17. Marine Environment Protection Committee (MEPC) and International Maritime Organization (IMO). ISO 8217: 2010 Revised Specification of Marine Fuels; Document Number MEPC61/4/1; MEPC and IMO: London, UK, 2010.

18. European Committee for Standardization (CEN). Automotive Fuels-Fatty Acid Methyl Esters (FAME) for Diesel Engines—Requirement Methods; EN 14214:2008; CEN: Brussels, Belgium, 2009.

19. Knudsen, O.F.; Hassler, B. IMO legislation and its implementation: Accident risk, vessel deficiencies and national administrative practices. Mar. Policy 2011, 35, 201-207.

20. Mahajan, A.; Ahluwalia, A.S.; Mahajan, P. Properties of biodiesel produced from various oilseeds. Int. J. Res. Environ. Sci. Technol. 2011, 1, 26-29.

21. International Maritime Organization (IMO). MARPOL Annex VI: Regulations for the Prevention of Air Pollution from Ships, Consolidated ed.; IMO: London, UK, 2006.

22. Muñoz, M.; Moreno, F.; Monné, C.; Morea, J.; Terradillos, J. Biodiesel improves lubricity of new low sulphur diesel fuels. Renew. Energy 2011, 36, 2918-2924.

23. National Renewable Energy Laboratory (NREL) and U.S. Department of Energy. Biodiesel Handling and Use Guide, 4th ed.; Report Number NREL/TP-540-43672; Office of Scientific and Technical Information: Oak Ridge, TN, USA, 2009.

24. Lin, C.Y.; Li, R.J. Fuel properties of biodiesel produced from the crude fish oil from the soapstock of marine fish. Fuel Proces. Technol. 2009, 90, 130-136.

25. Nabi, M.N.; Husted, J.E. Investigation of engine performance and emissions of a diesel engine with a blend of marine gas oil and synthetic diesel fuel. Environ. Technol. 2012, 33, 9-15.

26. Pinzi, S.; Mata-Granados, J.M.; Lopez-Gimenez, F.J.; Luque de Castro, M.D.; Dorado, M.P. Influence of vegetable oils fatty-acid composition on biodiesel optimization. Bioresour. Technol. 2011, 102, 1059-1065.

27. Mehta, P.S.; Anand, K. Estimation of a lower heating value of vegetable oil and biodiesel fuel. Energy Fuels 2009, 23, 3893-3898.

28. Fregolente, P.B.L.; Fregolente, L.V.; Wolf Maciel, M.R. Water content in biodiesel, diesel, and biodiesel-diesel blends. J. Chem. Eng. Data 2012, 57, 1817-1821.

(C) 2013 by the authors; licensee MDPI, Basel, Switzerland. This article is an open access article distributed under the terms and conditions of the Creative Commons Attribution license (http://creativecommons.org/licenses/by/3.0/). 